
\title{
25 Research Square \\ Use of CPP plastics to reduce the production costs in plant tissue culture technique
}

Kazem Kamali Aliabad ( $\square$ kkamali@yazd.ac.ir )

Yazd University https://orcid.org/0000-0002-7812-5212

Elahe Zamani

Yazd University

Aliakbar Vaghar

Yazd University

\section{Research Article}

Keywords: Cultivation containers, cultivated plastics, Economics in agriculture

Posted Date: March 3rd, 2022

DOI: https://doi.org/10.21203/rs.3.rs-1387420/v1

License: (1) This work is licensed under a Creative Commons Attribution 4.0 International License.

Read Full License 


\section{Abstract}

Plant tissue culture is one of the methods of plant propagation. Production costs in this method are relatively high. These costs include items such as the cost of culture vessels. This research aimed to investigate the replacement of new containers made of Cast Polypropylene (CPP) plastics instead of glass. For this study Petunia plant was selected as a model plant. In the first, all plants were disinfected. Then they were cultured in MS medium containing different amounts of $0,0.5,0.8$, and $1 \mathrm{mg} /$ I BAP which were made in different cultures of jam glasses, Test tubes, and CPP plastics containers. After establishment and proliferation stages, plants were transferred to a rooting medium supplemented by different concentrations of IBA and after 30 days, growth different factors were measured. The highest number and length of shoots and the highest number of leaves were obtained in $0.8 \mathrm{mg} / \mathrm{l} \mathrm{BAP}$ culture medium in CPP plastic containers and the lowest amount was in a test tube culture media. The effect of regulator amount and container type in the rooting stage was not significant.

\section{Introduction}

Petunia (Petunia spp.) is an annual and ornamental plant from the Solanaceae family. The origin of this plant is South America (Mexico and Argentina) which has potted cultivars suitable for cultivation in green spaces (Sastry et al., 2020).

In vitro culture technique is one of the best methods for propagating different plants, which the explants are separated from the mother plant and placed in a completely sterile and controlled media where light, pH, temperature, and humidity can be controlled and adjusted (Johns, 2019, Lakhera et al., 2018). Nowadays this technique is used for mass production and plant breeding all over the world. In general, there is great interest in using plant tissue culture techniques in the mass production of disease-free plants, rejuvenation, conservation of genetic resources, and development of clones (Lal, 2015). This technology requires expertise, financial capital, and energy. This method has many advantages but also disadvantages including high production costs which limit industrial and commercial systems. Thus, the low-cost tissue culture technique may be considered a priority strategy in the production of medicinal, ornamental, and garden plants for each country. To reduce costs during this method (without significant reduction in production quality), various strategies have been used by researchers (Datta, 2017).

Among the factors that increase production costs, we can refer to the type of container and the culture medium that is used, as well as costs of labor, sales and marketing, laboratory building, energy, equipment, distilled water, and laboratory materials. One of the important and effective limitations of this technique is the size of culture containers for the development of tissue culture plants (Chen., 2016).

In general, laboratory glass tubes are used for tissue culture research. These pipes have a small lid, so they are suitable for preventing contamination; however, no more than one or two plants can be grown in them. Also, the use of cone-shaped flasks is not recommended for growing the plant in the culture medium since they are too long and include a small lid. Therefore, for commercial production of the plant, 
larger containers made of transparent material with relatively large lids are needed. Large glass and plastic containers are used in the cultivation of plant tissue in developed countries; however, the higher cost of these containers in developing countries leads to a higher price in the production process, thus they are not economically viable. The use of planting containers that do not reduce the final quality of the plants can be considered an economically viable method for propagation. Transparency and light transmission efficiency, impermeability, and autoclave ability are some of the characteristics that should be considered in the selection of alternative culture containers. Producing containers having these characteristics with lower production costs can be regarded as a revolution in plant tissue culture. Choosing a suitable culture container is one of the important and key factors in the growth and development of plants under in vitro culture conditions and therefore special attention should be paid to it. In some cases, changes in the type of culture container can make good and appropriate changes in the explants and provide better conditions for their growth.

The purpose of this study was to investigate the effect of culture vessels made with CPP plastics instead of expensive glass containers and to compare the quantity and quality of plants grown in plastic or glass containers to introduce a container with a very reasonable price for plant cultivation. In this way, tissue culture will be greatly improved economically and plant production costs will be reduced. As a result, plants are available at a more reasonable price.

\section{Materials And Methods}

\section{Sampling and disinfection}

This experiment was performed in autumn, 2019 in the Biotechnology and Plant Tissue Culture Laboratory of Yazd University, Iran. Petunia spp. was selected as a model plant for this study. This plant is widely used in experiments to study the effects of different substances and conditions. In the beginning, healthy and virus-free petunia plants were obtained from one of the reputable greenhouses in Yazd, and then 1.5-cm-long samples were taken from their shoots. Then, the samples were disinfected under the laminar hood. Disinfectants were prepared for petunia explants. To prepare these materials, 4 glasses were picked and each was filled with $100 \mathrm{cc}$ of distilled water. Next, $0.1 \%$ of mercury chloride was added to one of the glasses while the others were left only with distilled water. Then, the 4 glasses were placed in an autoclave for decontamination with a temperature of $121^{\circ} \mathrm{C}$ and a pressure of $15 \mathrm{psi}$ for 10 minutes. At the end of 10 minutes, the 4 glasses were brought to ambient conditions and cooled. After cooling, the prepared explants from the mother plant were disinfected in a completely sterile condition under a laminar hood. First, the explants were placed into one of the water-containing glasses for 3 minutes. In the next step, the explants were placed in a glass containing distilled water and mercury chloride for 3 minutes, and then they were rinsed for 3 minutes to remove the remained contamination and eliminate the effects of mercury chloride. The rinsing process was repeated two times.

\section{Construction of culture medium}


For Petunia samples culture, the MS medium culture was considered. The Media containing different amounts of BAP growth regulators were used in the propagation phase, and media containing different amounts of IBA were used in the rooting phase. Different concentrations of $0,0.5,0.8$, and $1 \mathrm{mg} /$ I BAP were added to MS culture media and finally, after combining all the materials needed to make the culture medium, different treatments of MS culture medium with different amounts of proliferation and rooting regulators were prepared. The amount of agar used for culture media was $5 \mathrm{~g} / \mathrm{I}$ and the amount of sucrose used was $25 \mathrm{~g} / \mathrm{I}$. On the other hand, the MS culture media with different amounts of BAP $(0.2$, $0.5,0.8$, and $1 \mathrm{mg} / \mathrm{l})$ were placed in different types of containers such as ordinary jam glass, McCarthy glass, and containers made of CPP plastic. In other words, each medium with a specific concentration of growth regulator was poured into three specific containers separately. Finally, the culture media were placed in an autoclave for 12 minutes to be disinfected. Then, they were transferred to a laboratory environment and became semi-solid and jelly-like after 15 minutes.

\section{Cultivation and conservation}

After disinfecting the explants, the samples were transferred to culture media using sterile forceps in a sterile condition under laminar hood McCarthy glass and jam jars' lids were sealed using paraffin after the planting process. Containers made of CPP plastic, as newly designed culture dishes, were taken under the hood and their upper parts were cut using scissors. After the explants were cultured, the containers' upper parts were sewn using a heating device. Then, the samples were cultured in various dishes, each one containing a different amount of growth regulators. Next, they were transferred to a clean room with controlled light conditions of 3000 lux and a temperature of $25^{\circ} \mathrm{C}$. After proliferation was sufficient, the samples were transferred to different types of containers including the different amounts of IBA growth regulator to rooting. By the time the explants were inoculated, they were transferred to new culture media containing regulators of IBA auxin growth. At first, they were kept in dark chambers for 4 days and then transferred to light conditions.

\section{Trait assessment, data collection, and analysis}

30 days after the transfer of explants to different culture dishes containing different concentrations of growth stimulant cytokinin BAP, traits such as number of shoots, number of leaves, and root length were measured in all treatments. Also, 30 days after the transfer of explants to different types of culture media containing various concentrations of IBA auxin regulator, traits such as root number, root length, number of shoots, and shoot length were measured. A ruler was used to measure the different lengths of shoots and roots. The number of leaves and roots was also counted by numerical counting. After normalizing the data, they were analyzed using SPSS20 software and their mean difference was compared using the Duncan test.

\section{Results}

Variance analysis was performed on the effect of BAP concentration, container type, and the interaction effect of BAP concentration and container type on traits such as shoots number, shoots length, and 
leaves number per explants of Petunia spp. under in-vitro conditions. The results showed that the effect of different concentrations of BAP, type of culture container, and the interactions of the two on the shoots number, shoot length, and leaves number at the level of $5 \%$ was significant (Table 1 ).

Table 1

Variance analysis of the different concentrations of BAP with different types of vessels and their interactive effect on shoots number, shoots length, and leaves number per explants of Petunia spp. under in-vitro conditions

\begin{tabular}{|lllllll|}
\hline Characteristics & SOV & df & SS & MS & F & Sig \\
\hline Shoot number & BAP & 3 & 174.556 & 58.185 & 19.042 & 0.000 \\
& Vessels & 2 & 330.167 & 165.083 & 54.027 & 0.000 \\
& interactive & 6 & 182.944 & 30.941 & 9.979 & 0.000 \\
& Error & 24 & 73.333 & 3.056 & & \\
Shoot length & BAP & 3 & 15.008 & 5.005 & 14.453 & 0.000 \\
& Vessels & 2 & 66.051 & 33.025 & 95.418 & 0.000 \\
& interactive & 6 & 44.912 & 7.485 & 21.627 & 0.000 \\
& Error & 24 & 8.307 & 0.346 & & \\
\hline Leaf number & BAP & 3 & 23589.639 & 7863.213 & 36.715 & 0.000 \\
& Vessels & 2 & 35378.167 & 17689.083 & 82.595 & 0.000 \\
& interactive & 6 & 37322.944 & 6220.491 & 29.045 & 0.000 \\
& Error & 24 & 5140.000 & 214.167 & & \\
\hline
\end{tabular}

Variance analysis of different IBA concentrations, type of culture container, and interactions of these factors on traits such as roots number, roots length, shoots number, and shoots length was performed. According to the results of variance analysis, the effect of different concentrations of IBA and culture container type on the number of the roots of explants was not significant, but the interaction of different concentrations of IBA and culture container type on the number of the roots in explants was considered significant. In addition, the effect of different concentrations of IBA on root length in explants was not significant, but the effect of culture container type and the interaction effects of IBA concentration and culture container type on root length of explants were significant at the level of $5 \%$. The effects of different concentrations of IBA, culture container type, and their interactions on shoots number and leaves number were not significant in any part. The effect of planting containers on shoot length was significant at the level of $5 \%$, but the effect of IBA and the interaction effects of IBA and culture container type on shoot length was not significant (Table 2). 
Table 2

Variance analysis of the different concentrations of IBA with different types of vessels and their interaction on the number of roots, length of roots, shoots number, shoots length, and leaves number per explants of Petunia spp. explants under in-vitro condition.

\begin{tabular}{|c|c|c|c|c|c|c|}
\hline Characteristics & sov & df & SS & MS & $F$ & Sig \\
\hline \multirow[t]{4}{*}{ Root number } & IBA & 3 & 25.556 & 8.519 & 0.555 & 0.650 \\
\hline & Vessels & 2 & 2.000 & 1.000 & 0.065 & 0.937 \\
\hline & Interactive & 6 & 243.778 & 40.630 & 2.645 & 0.041 \\
\hline & Error & 24 & 368.667 & 15.361 & & \\
\hline \multirow[t]{4}{*}{ Root length } & IBA & 3 & 0.781 & 0.260 & 0.056 & 0.982 \\
\hline & Vessels & 2 & 68.821 & 34.410 & 7.431 & 0.003 \\
\hline & interactive Error & 6 & 97.268 & 16.211 & 3.501 & 0.012 \\
\hline & & 24 & 111.133 & 4.631 & & \\
\hline \multirow[t]{4}{*}{ Shoot number } & IBA & 3 & 1.556 & 0.519 & 0.812 & 0.500 \\
\hline & Vessels & 2 & 1.056 & 0.528 & 0.826 & 0.450 \\
\hline & interactive Error & 6 & 4.944 & 0.824 & 1.290 & 0.299 \\
\hline & & 24 & 15.333 & 0.639 & & \\
\hline \multirow[t]{4}{*}{ Shoot length } & IBA & 3 & 0.483 & 0.161 & 0.254 & 0.858 \\
\hline & Vessels & 2 & 35.787 & 17.894 & 28.216 & 0.000 \\
\hline & interactive Error & 6 & 7.679 & 1.280 & 2.018 & 0.103 \\
\hline & & 24 & 15.220 & 0.634 & & \\
\hline \multirow[t]{4}{*}{ Leaf number } & IBA & 3 & 80.750 & 26.917 & 0.803 & 0.505 \\
\hline & Vessels & 2 & 156.722 & 78.361 & 2.337 & 0.118 \\
\hline & interactive Error & 6 & 260.833 & 43.472 & 1.297 & 0.296 \\
\hline & & 24 & 804.667 & 33.528 & & \\
\hline
\end{tabular}

Due to a large number of treatments, before describing the mean comparisons, the treatments are given in letters and numbers in the following tables (Tables 3 and 4). 
Table 4

proliferation treatments of Petunia spp. explants

\begin{tabular}{|lccc|}
\hline BAP mg L & \multicolumn{1}{l}{ Vessels } & & \\
\cline { 2 - 4 } & Jam vessels & (McCarthy) & Plastic bag (CCP) \\
\hline 1 & $\mathrm{~T} 1$ & $\mathrm{~T} 2$ & $\mathrm{~T} 3$ \\
0.8 & $\mathrm{~T} 4$ & $\mathrm{~T} 5$ & $\mathrm{~T} 6$ \\
\hline 0.5 & $\mathrm{~T} 7$ & $\mathrm{~T} 8$ & $\mathrm{~T} 9$ \\
\hline 0 & $\mathrm{~T} 10$ & $\mathrm{~T} 11$ & $\mathrm{~T} 12$ \\
\hline
\end{tabular}

Table 5

Rooting treatments of Petunia spp. explants

\begin{tabular}{|c|c|c|c|}
\hline \multirow[t]{2}{*}{ IBA mg L-1 } & \multicolumn{3}{|l|}{ Vessels } \\
\hline & Jam vessels & (McCarthy) & Plastic bag (CCP) \\
\hline 1 & T1 & $\mathrm{T} 2$ & T3 \\
\hline 0.8 & $\mathrm{~T} 4$ & T5 & T6 \\
\hline 0.5 & T7 & T8 & T9 \\
\hline 0.2 & T10 & T11 & T12 \\
\hline
\end{tabular}

The mean comparison effect of cultivated container type on shoots length showed that this effect was significant. In other words, there was a significant difference in the length of the grown shoots in the three types of jam glass, McCarthy glass, and CPP plastic containers. Most of the shoot lengths were related to explants grown in culture medium in CPP plastic containers, which was significantly different from the shoot length of explants grown in culture medium in the other two containers. After CPP plastics (T3) containers, jam glass containers had the highest shoot length of explants (T1) which were significantly different from the hoot length of explants inside McCarthy glasses (T2) containers (Fig. 1).

In addition, the effect of culture type on root length was significant, so that the highest root length was observed in the explants in CPP plastic culture containers and jam jars and the lowest root length was shown in the McCarthy container explants (Fig. 2).

Mean comparison interaction of BAP and culture container type on leaves number showed that the highest leaves number at a concentration of $0.8 \mathrm{mg}$ / I BAP was in CPP plastic containers (T6) which were significantly different from other treatments in terms of leaves number. Then, the treatment of culture medium with concentrations of 1 and $0.5 \mathrm{mg}$ / I BAP in CPP plastic containers (T3 and T9) showed the highest leaves number in the explants, which was significantly different from the first treatment (T6). Other treatments were significantly different from $T 3, T 6$, and T9 but they were not 
significantly different from each other. Therefore, it can be said that in terms of leaves number, culture container type in different concentrations of BAP had the highest leaves number in explants (Fig. 3).

Also, according to the results of the mean comparison, the interaction of BAP and the culture container type on the shoot length showed that the highest shoot length was related to the treatment of culture media with $0.8 \mathrm{mg} / \mathrm{I} \mathrm{BAP}$ in CPP plastic containers (T6). There was a statistically significant difference among the treatments. After this treatment, the media treatment with $0.5 \mathrm{mg} / \mathrm{l} \mathrm{BAP}$ and the control treatment, which were placed in CPP plastic containers (T9 and T12 treatments), had the highest shoot length in the explants. The lowest shoot length was related to $0.8 \mathrm{mg} / \mathrm{l}$ BAP treatment in McCarthy glass (T5 treatment) (Fig. 4).

The results also suggested that the highest shoot number was $0.8 \mathrm{mg} / \mathrm{BAP}$ in CPP plastic containers (T6 treatment) and then in 1 and $0.5 \mathrm{mg} / \mathrm{I} \mathrm{BAP} \mathrm{in} \mathrm{CPP} \mathrm{plastic} \mathrm{containers} \mathrm{(} \mathrm{T3} \mathrm{and} \mathrm{T9} \mathrm{treatments)} \mathrm{(Fig.} \mathrm{5).}$

\section{Discussion}

The concept of cost reduction technology in tissue culture meant better use of resources in tissue culture technology, with the lowest cost and highest efficiency. The shoot length, growth rate, and fresh weight of tissue culture plants varied depending on the culture container type used (Datta et al., 2017). The use of CPP disposable plastics for the production of tissue culture plants on a large scale was very costeffective because it did not have the cost of washing and breaking dishes, and they also took up less space, and they were easier to work with because of their low weight. Also, the size of the culture container affected the growth traits of the explants as well as the shoot length. This factor could affect the growth and development of glass samples by making changes in the composition of in vitro gases and light permeability. Therefore, the affected plant traits such as shoot length, amount and rate of micropropagation, fresh and dry weight, and vitrification of the plants (Sax et al, 2005).

Emrani Dehkehan et al (2017) by experimenting on Solanum melongena L.showed that the effect of different crops on the shoot length, average root length, and weight of microtubers in seedlings was significant, so there was a significant difference among different crops in terms of changes in the plants. These results were completely consistent with the results of this experiment. The researchers also stated that there was a significant difference among the treatment of different cropping containers in terms of leaf number, leaf size, root number, and several microtubers, so that their best condition was in the treatment of ship containers with polypropylene.

The results of Kernova and Popovo (2007) on Prunus persica micropropagation and the results of Kakar et al. (2010) on Musa sapientum micropropagation also confirmed the better growth of plants in propylene cast containers. Since there was a difference in the volume of air above the culture medium in different culture vessels, there was a difference in the gas exchange between the medium and the atmosphere in different containers, and this difference affected the growth of the samples. The air above the samples contained compounds such as large amounts of ethylene, which could greatly stimulate or inhibit wet weight gain in the explant (Bin Bakri et al, 2017). 
Containers used for in vitro culture generally influenced plant growth that did not receive much attention. This effect was due to the interaction of many factors that ultimately caused changes in different characteristics of the crop. Culture containers that provided more air movement had less shoot necrosis (Bin Bakri et al, 2017).

The shoot length, propagation rate, and fresh weight of micropropagation plants varied in different culture containers (Mackay and Kitto, 1988; McClelland and Smith, 1990). According to the reports, changing the volume, size, and shape of the culture medium affected the rate of propagation, shoot yield, and plant morphology (Ivanicka, 1987). The effect of culture medium size on explants was considered significant. McLeland and Smith (1990) stated that as the volume of the culture medium increased, the shoots became denser and their root capacity increased. Larger culture media resulted in larger leaf plants and increased root production (McDonald et al, 1985). In this experiment, culture media in containers made of CPP plastic had the same volume of the medium as the others but spread this volume over a wider area, and this could be one of the reasons for the superiority of explants grown in these media compared to other media.

\section{Conclusion}

In general, it can be said that the plants in CPP plastic containers had a good longitudinal growth compared to the conventional containers in plant tissue culture, and this increase in the quality and quantity of growth was significantly different from other culture containers. Very good growth of plants grown in CPP containers compared to other containers can have various reasons such as increasing the level of light transmission or creating a better gas composition inside the interior for better and more plant growth. Moreover, other advantages of these containers are being cheap, light, easier portability, and occupying less space. It is interesting to know that in these plastic containers, there is a possibility of gas exchange between in vitro and in vivo space so that no microorganisms enter but the gas exchange is done which consequently causes the internal humidity of the container and gases such as ethylene to be in an optimal state, resulting in optimal growth and development. Therefore, choosing the right cultivation container, as well as improving the quantitative and qualitative characteristics of the plants will make it possible to save money economically and do something with the least production cost.

\section{Declarations}

\section{Declarations}

Conflict of interest The authors have no conficts of interest to declare that are relevant to the content of this article.

\section{Funding}

This research received no external funding. 


\section{References}

1. -Bin Bakri MK, Jayamani E, Soon KH, Hamdan S, Kakar A (2017) An experimental and simulation studies on sound absorption coefficients of banana fibers and their reinforced composites. Nano hybrids and composites, vol 12. Trans Tech Publications Ltd, pp 9-20

2. -Chen SL (2016) Economic costs of hemophilia and the impact of prophylactic treatment on patient management. Am J Manag Care 22(5 Suppl):s126-s133

3. -Datta SK, Chakraborty D, Janakiram T (2017) Low cost tissue culture: an overview. J Plant Sci Res 33(2):181-199

4. -Emrani Dehkehan M, Moieni A, Movahedi Z (2017) Effects of zeatin riboside, mannitol and heat stress on eggplantn (Solanum melongena L.) anther culture. Iran J Genet Plant Breed 6(1):16-26

5. -Johns AE (2019) Lessons for Plant Micropropagation. Educreation Publishing

6. -Kakar S (2010) The Crimson Throne. Penguin Books India

7. -Kernová V, Komárek V, Kubrichtová L, Režná P, Sýkorová K, Štundlová D, TANDLER J (2007) Výchova ke zdravé výživě dětí a mládeže v Euroregionu Nisa. Liberec: Venkovský prostor, op s

8. -Lakhera K, Kumar A, Rani A, Dixit R, Rana S (2018) Plant tissue culture and its application. Bull Pure Appl Sciences-Botany 37(1):32-36

9. -Lal M, Tiwari AK, Gupta GN (2015) Commercial scale micropropagation of sugarcane: constraints and remedies. Sugar Tech 17(4):339-347

10. -Mackay WA, Kitto SL (1988) Factors affecting in vitro shoot proliferation of French tarragon. J Am Soc Hortic Sci 113(2):282-287

11. -McDonald TP, Cottrell M, Clift R, Khouri JA, Long MD (1985) Studies on the purification of thrombopoietin from kidney cell culture medium. J Lab Clin Med 106(2):162-174

12. -Sastry KS, Mandal B, Hammond J, Scott SW, Briddon RW, Sastry KS, Mandal B, Hammond J, Scott SW, Briddon RW (2019) Petunia spp. Encyclopedia of Plant Viruses and Viroids, pp.1781-1793

13. -Sax PE, Islam R, Walensky RP, Losina E, Weinstein MC, Goldie SJ, Sadownik SN, Freedberg KA (2005) Should resistance testing be performed for treatment-naive HIV-infected patients? A costeffectiveness analysis. Clinical infectious diseases, 41(9), pp.1316-1323

\section{Table}

Table 3 is not available with this version

\section{Figures}




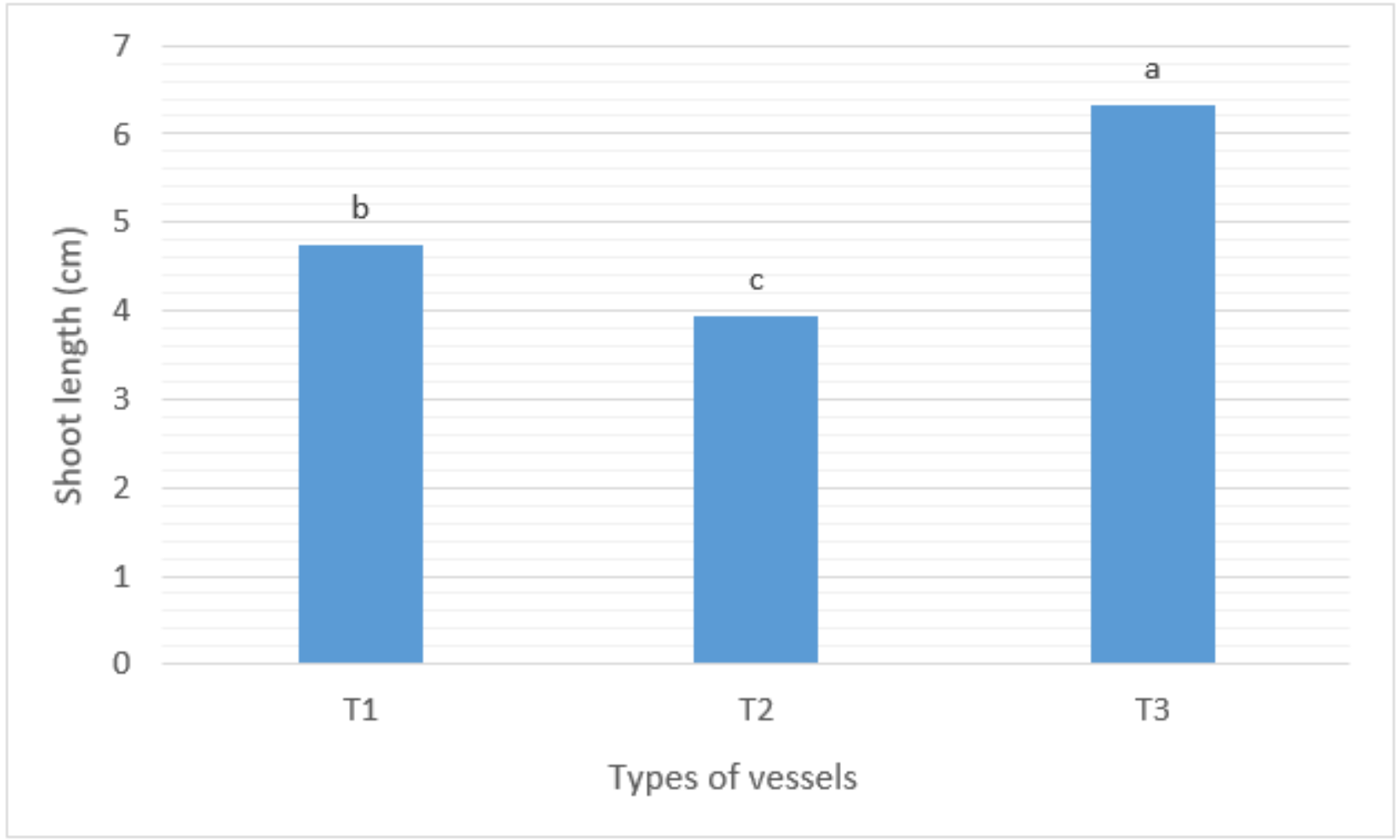

\section{Figure 1}

Mean comparison of different types of vessels, effect on shoots length of Petunia spp. explants under invitro conditions

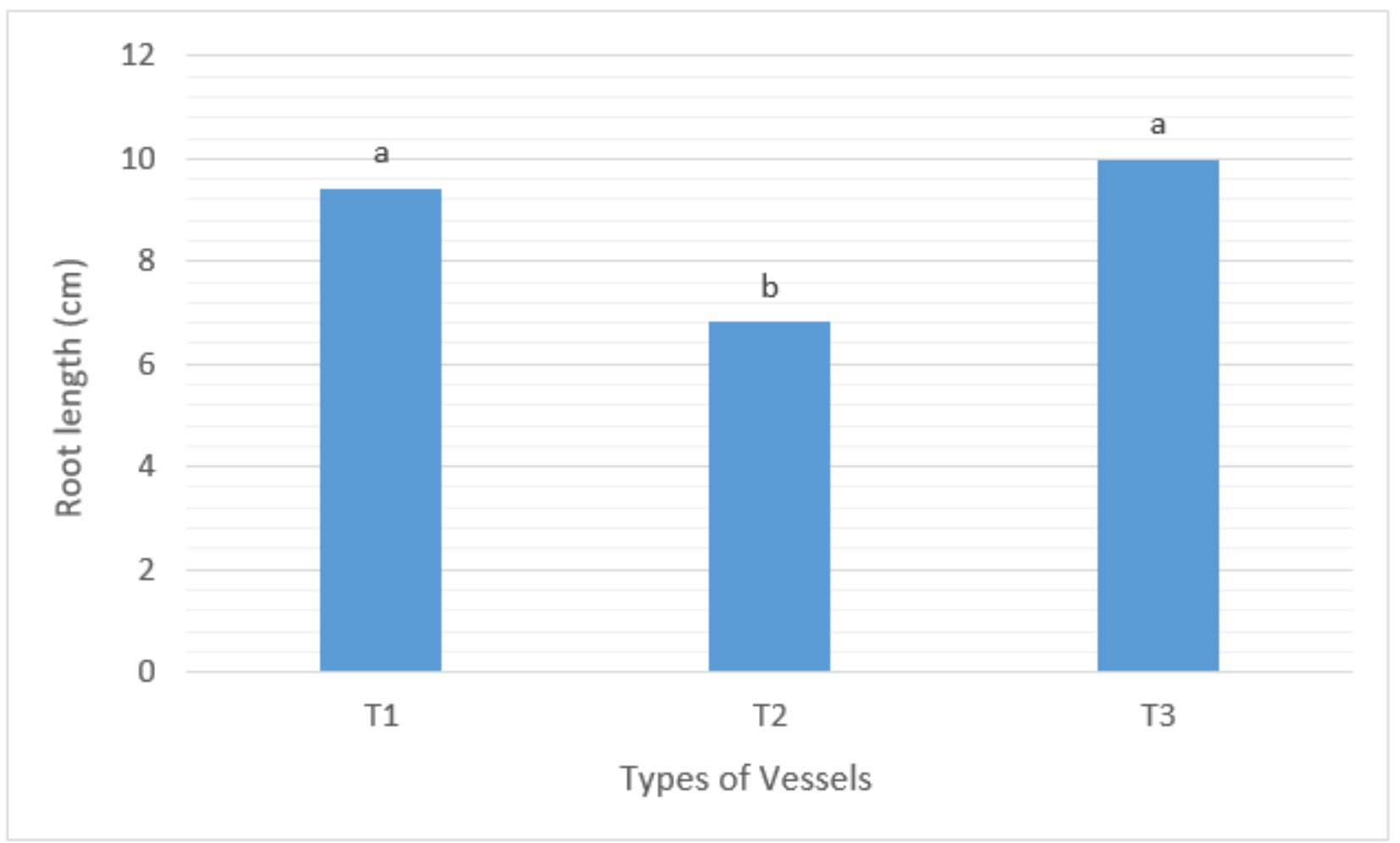


Figure 2

Mean comparison of different type's vessels, effect on root length of Petunia spp. explants under in-vitro conditions

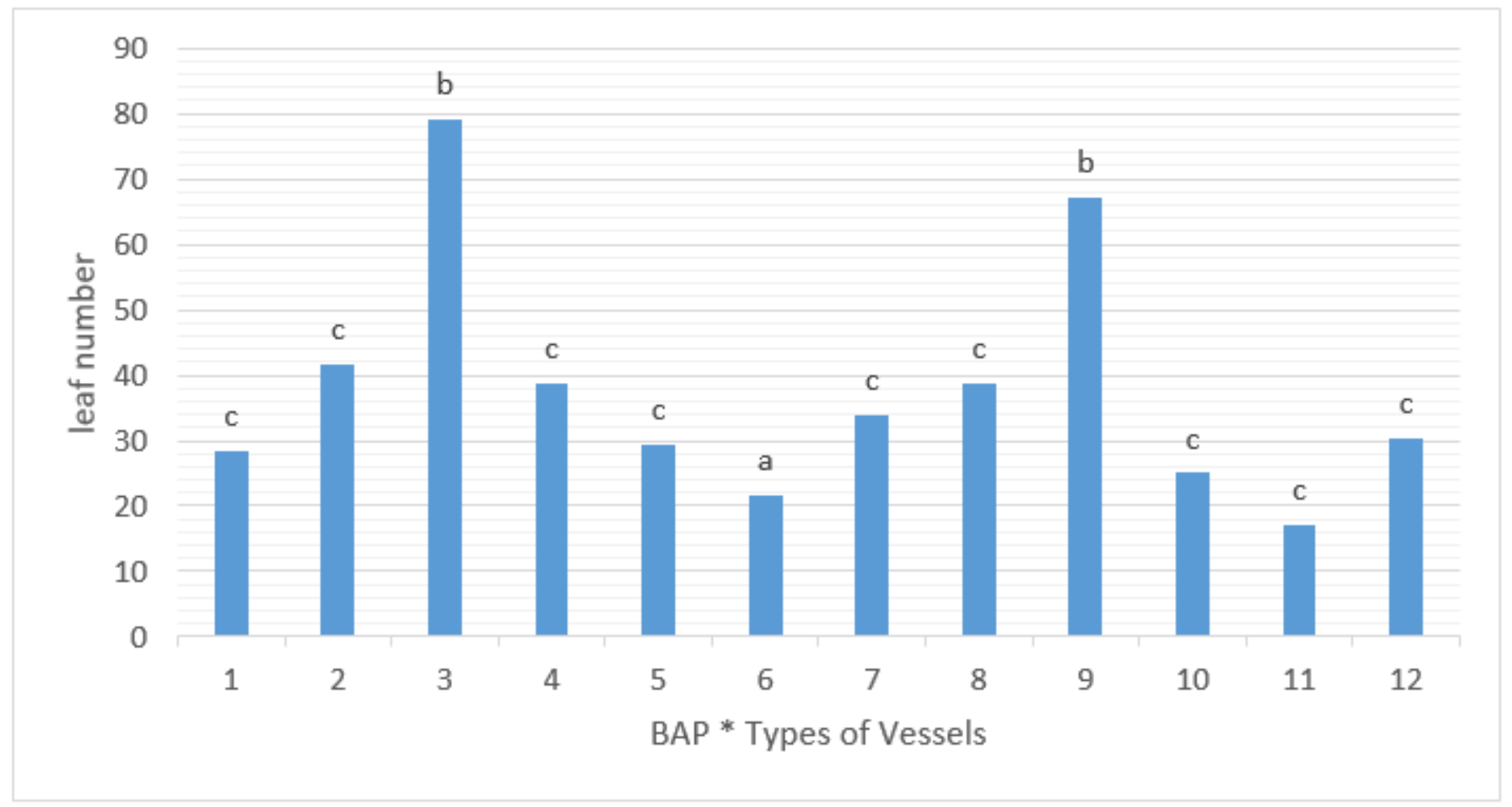

\section{Figure 3}

Mean comparison of different types of vessels with different concentration of BAP and their interactions on the laves number of Petunia spp. explants under in-vitro conditions 


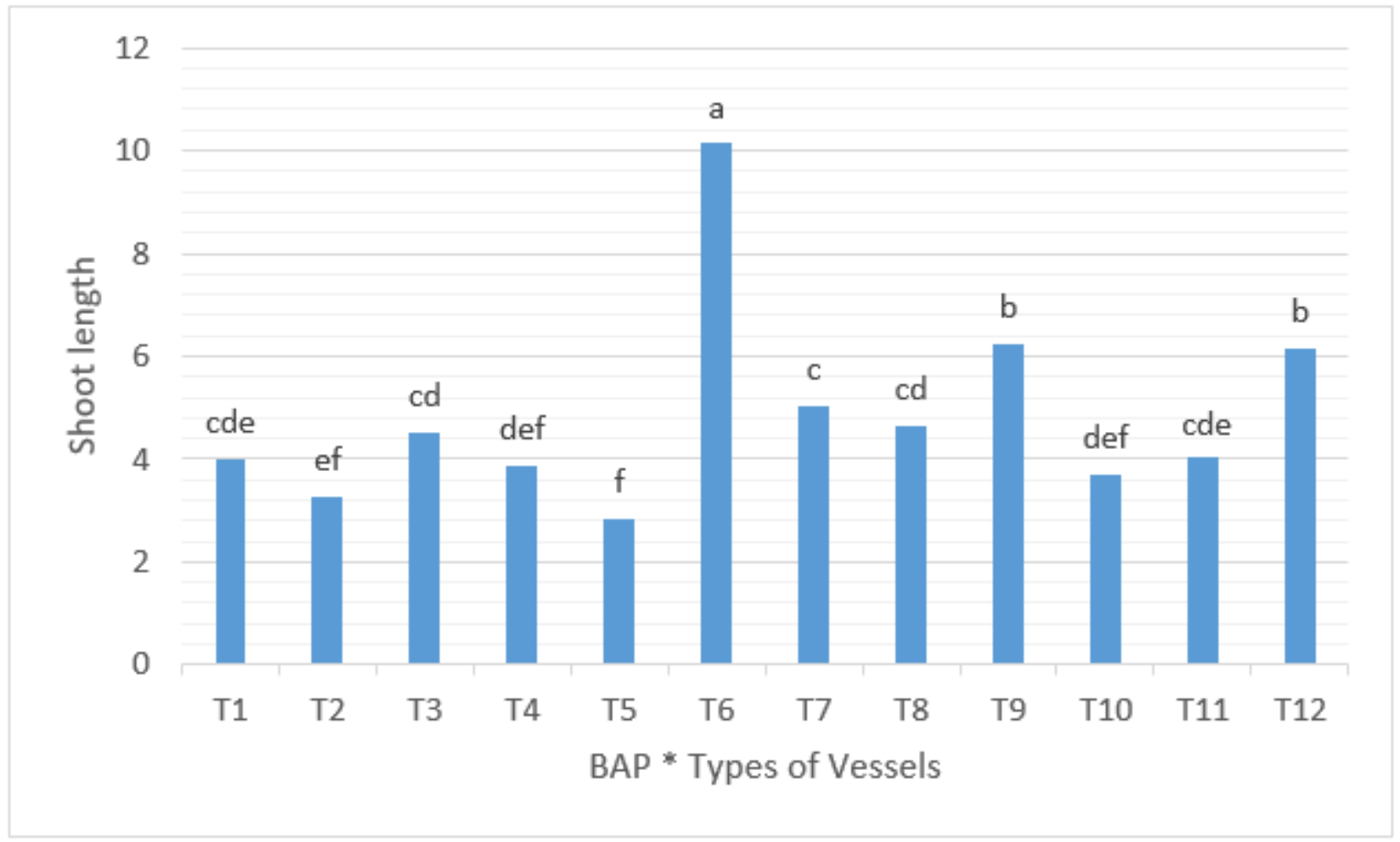

\section{Figure 4}

Mean comparison of different types of vessels with different concentration of BAP and their interactions on the Length of shoots of Petunia spp. explants under in-vitro conditions

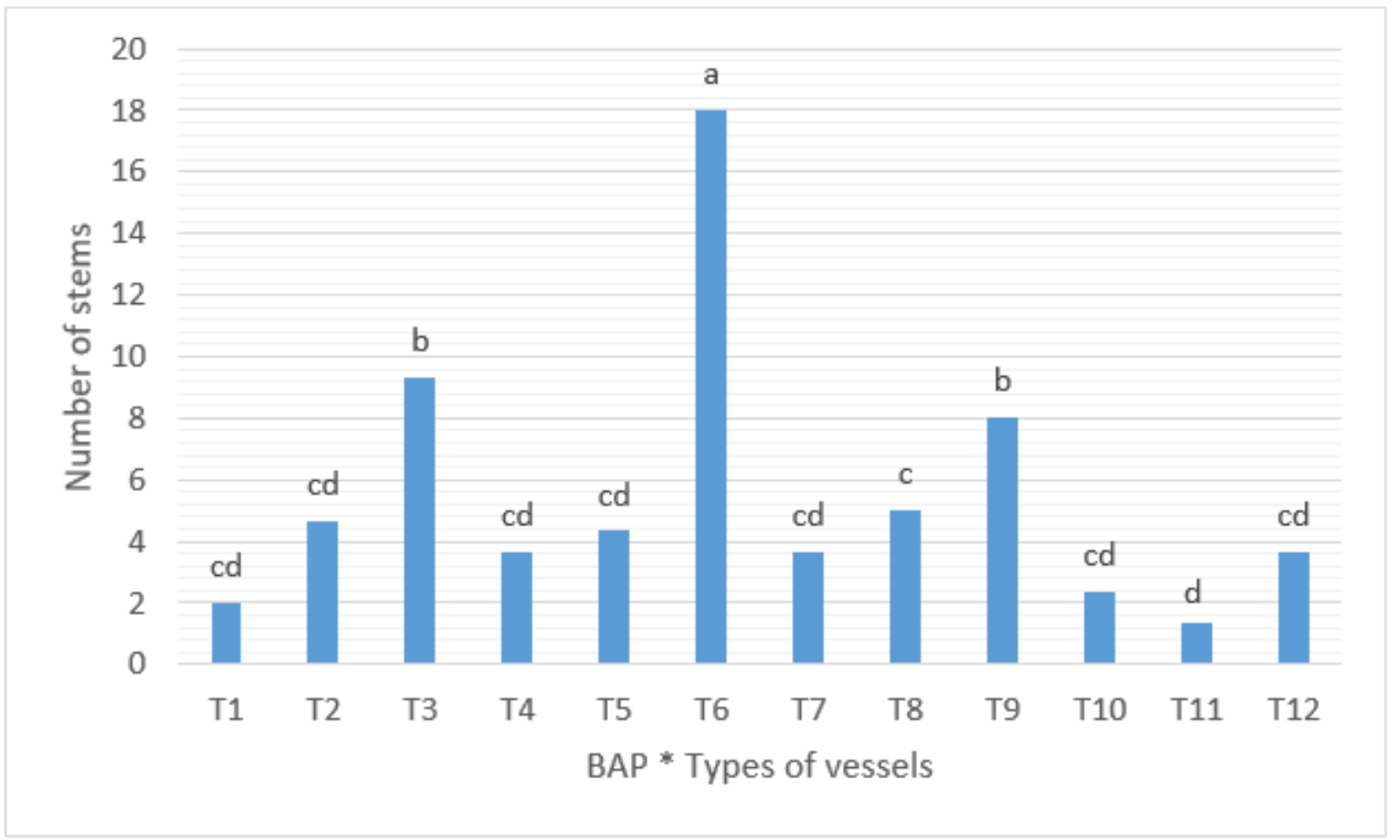

Page $13 / 14$ 


\section{Figure 5}

Mean comparison of different types of vessels with different concentration of BAP and their interactive on number of shoots of Petunia spp. explants under the in-vitro condition 